\title{
Age-dependent Distribution of Fungal Endophytes in Panax ginseng Roots Cultivated in Korea
}

\author{
Young-Hwan Park ${ }^{1}$, Young-Chang Kim², Sang Un Park ${ }^{3}$, Hyoun-Sub Lim , Joon Bum Kim ${ }^{5}$, \\ Byoung-Kwan $\mathrm{Cho}^{6}$, and Hanhong Bae ${ }^{1^{*}}$ \\ ${ }^{1}$ School of Biotechnology, Yeungnam University, Gyeongsan 712-749, Korea \\ ${ }^{2}$ Department of Herbal and Crop Research, National Institute of Horticultural and Herbal Science, Rural Development \\ Administration, Eumseong 369-871, Korea \\ ${ }^{3}$ Department of Crop Science, Chungnam National University, Daejeon 305-754, Korea \\ ${ }^{4}$ Department of Applied Biology, Chungnam National University, Daejeon 305-764, Korea \\ ${ }^{5}$ Warm-Temperate Forest Research Center, Korea Forest Research Institute, Seogwipo 697-050, Korea \\ ${ }^{6}$ Department of Biosystems and Machinery Engineering, Chungnam National University, Daejeon 305-764, Korea
}

Fungal endophytes were isolated from 1-, 2-, 3-, and 4-year-old ginseng roots (Panax ginseng Meyer) cultivated in Korea. The isolated fungal endophytes were identified based on sequence analysis of the internal transcribed spacer and morphological characterization by microscopic observations. A total of 81 fungal endophytes were isolated from 24 ginseng roots. Fungal endophytes were classified into 9 different fungal species and 2 unknown species. Ginseng roots that were 1-, 2-, 3-, and 4-years old were colonized by 2, 6, 8, and 5 species of fungal endophytes, respectively. While Phoma radicina was the most frequent fungal endophyte in 2-, 3-, and 4-year-old ginseng roots, Fusarium solani was the dominant endophyte in 1-year-old ginseng roots. The colonization frequencies (CF) varied with the host age. The CF were 12\%, 40\%, 31\%, and 40\% for 1-, 2-, 3-, and 4-year-old ginseng roots, respectively. We found a variety of fungal endophytes that were distributed depending on the age of ginseng plants.

Keywords: Panax ginseng, Fungal endophytes, Internal transcribed spacer sequence

\section{INTRODUCTION}

Fungal endophytes are considered to be a group of fungi that live asymptomatically inside the tissues of living plants [1-3]. Fungal endophytes do not penetrate plant cells, but instead grow in the spaces between plant cells or within plant cell walls, while utilizing low levels of nutrients in intercellular fluids and causing no obvious damage $[2,3]$. Recent studies have reported that fungal endophytes are ubiquitous in most plants and even lichens $[1,2,4]$. Endophytes are potential genetic sources

(c) This is an Open Access article distributed under the terms of the Creative Commons Attribution Non-Commercial License (http://creativecommons.org/licenses/by-nc/3.0/) which permits unrestricted non-commercial use, distribution, and reproduction in any medium, provided the original work is properly cited. of natural products for pharmaceutical, agricultural, and industrial purposes. Endophytes from medicinal plants such as ginseng might produce important secondary metabolites for bioactive materials.

In general, fungal endophytes are classified into 2 major groups: clavicipitaceous endophytes and nonclavicipitaceous endophytes. The clavicipitaceous endophytes are transmitted by seeds, but the mechanism for infection into hosts is still speculative. The nonclavicipitaceous

Received 17 Jan. 2012, Revised 01 May. 2012, Accepted 01 May. 2012

*Corresponding author

E-mail: hanhongbae@ynu.ac.kr

Tel: +82-53-810-3031, Fax: +82-53-810-4769 
endophytes found in woody and herbaceous plants provide the potential for a wide variety of direct and indirect interactions between plants and herbivores, including increasing resistance to disease, abiotic stress and the enhancement of plant growth [4]. Fungal endophytes are significant because they produce a wide variety of secondary metabolites with potential uses in medicine, agriculture, and industry. Compounds produced by fungal endophytes include alkaloids, terpenoids, flavonoids, and steroids. These compounds can be used for growth promotion of host plants, enhancement of the synthesis of secondary metabolites of host plants, and to help plants defend against pathogens [5-7]. Thus, there is a great opportunity to identify novel metabolites produced by endophytes.

Panax ginseng Meyer belongs to the Araliaceae family and is a perennial umbel plant. It has been used for thousands of years as an important source of medicinal herbs. In Asia, ginseng is known as the most valuable medicinal plant. In general, ginseng is a shade-loving plant, with one stalk having 5-fingered leaves, white flowers, red to yellow fruits and pale yellow root [8]. Despite the fact that active compounds are present in all parts of the ginseng plant, only the root is used pharmacologically. Ginseng contains triterpene glycosides, commonly referred to as ginsenosides, compared to saponins contained in other plants. Many active ingredients are found in all parts of the plant, including amino acids, phenols, alkaloids, polypeptides, and vitamins. Ginseng has many proven pharmacological effects such as improvement of cerebral function, immune modulation, pain relief, diabetes, and cancer prevention [8-10]. The components and contents of ginsenosides are influenced by many factors such as the species, age, plant tissue, cultivation environment, and harvest season. The cultivation of ginseng can be problematic because ginseng is affected by soil conditions during long periods of cultivation. One of the major problems is diseases caused by pathogenic fungi due to long periods of cultivation in the same soil $[11,12]$. Ginseng can be affected by many fungal pathogens such as gray mold produced by Botrytis cinerea, alternaria blight produced by Alternaria panax, anthracnose produced by Colletotrichum gloeosporioides, sclerotinia white rot produced by Sclerotinia sp., phytophthora blight produced by Phytophthora cactorum, and root rot produced by Cylindrocarpon destructans $[13,14]$. Control of these fungal pathogens is a challenge for most ginseng cultivators. The aim of this study was to examine the diversity of fungal endophytes obtained from different ages of $P$. ginseng cultivated in Korea. The results can be further used for protection of ginseng plants and/or production of bioactive metabolites.

\section{MATERIALS AND METHODS}

\section{Collection of ginseng roots}

Ginseng roots of 1-, 2-, 3-, and 4-year-old plants were harvested from the National Institute of Horticultural and Herbal Science (Eumseong, Korea), which is located in latitude $36^{\circ} 56^{\prime} \mathrm{N}$ and longitude $127^{\circ} 45^{\prime} \mathrm{E}$. Ginseng plants were cultivated according to the protocol of 'ginseng Good Agricultural Practice standard cultivation guide' [15] developed by the Rural Development Administration, Korea. The soil type was sandy loam with $\mathrm{pH}<5.8$ and electrical conductivity (EC) $0.6 \mathrm{dS} / \mathrm{m}$. Fungicides were sprayed 3 to 6 times per year. Harvest of the ginseng plants was made in September 2010. Whole roots including rhizomes, main roots and hairy roots were used in this study. Six roots of ginseng plants were used for each age of plant (24 plants in total). Harvested ginseng plants were stored at $4^{\circ} \mathrm{C}$ prior to use.

\section{Isolation of fungal endophytes}

Ginseng roots were washed under running tap water for $5 \mathrm{~min}$ to remove soil and debris and root samples were cut into $10 \times 10 \mathrm{~mm}$ segments using a sterilized blade. All root segments were surface sterilized in $75 \%$ ethanol for $1 \mathrm{~min}$, transferred to $4 \% \mathrm{NaHCO}_{3}$, washed for $10 \mathrm{~min}$, and then placed in $75 \%$ ethanol for $30 \mathrm{~s}$. The sterilized root segments were washed 3 times in sterile distilled water for $1 \mathrm{~min}$ and blotted onto a sterile paper towel. Root segments were then transferred to potato dextrose agar (PDA) plates (Difco, Sparks, MD, USA) with $200 \mathrm{mg} / \mathrm{mL}$ each of ampicillin and streptomycin to inhibit bacterial growth. Plates were incubated at room temperature, and fungal colonies growing from the edges of the root segments were transferred to new PDA plates containing ampicillin and streptomycin. Transfer of fungal colonies from the root segments was continued for up to $4 \mathrm{wk}$, and the fungal isolates were stored in $10 \%$ glycerol at $-80^{\circ} \mathrm{C}$ for long-term storage.

\section{Identification of fungal endophytes}

Morphological identification of isolated fungal endophytes was done by characterization of spores and hyphae using light microscope (Olympus BX51; Olympus, Tokyo, Japan). Fungal mycelia were scraped from PDA plates and ground into a fine powder using a mortar and pestle in liquid nitrogen and sea sand. A DNeasy Plant Mini kit (Qiagen, Valencia, CA, USA) was used to ex- 
Table 1. Putative taxonomic affinities and the CF of the isolated fungal endophytes from ginseng roots

\begin{tabular}{|c|c|c|c|c|c|c|}
\hline \multicolumn{3}{|c|}{ ITS BLAST results } & \multirow{2}{*}{\multicolumn{4}{|c|}{$\begin{array}{c}\% \mathrm{CF}(\mathrm{NI}) \\
\text { Root age (yr) }\end{array}$}} \\
\hline \multirow{2}{*}{ Closest match } & \multirow{2}{*}{ Accession no. ${ }^{1)}$} & \multirow{2}{*}{ Max identity (\%) } & & & & \\
\hline & & & 1 & 2 & 3 & 4 \\
\hline Trichoderma citrinoviride & HM776434 & 100 & $5(2)$ & & & \\
\hline Colletotrichum panacicola & GU935869 & 100 & & $4(2)$ & & \\
\hline Phoma radicina & FJ427058 & 100 & & $15(8)$ & $11(8)$ & $21(17)$ \\
\hline unknown 1 & HM042312 & 100 & & $5(3)$ & $3(2)$ & $9(7)$ \\
\hline Fusarium acuminatum & HM776425 & 100 & & & $3(2)$ & \\
\hline unknown 2 & AB499792 & 99 & & & $3(2)$ & \\
\hline Fusarium oxysporum & HM210092 & 100 & & $5(3)$ & $3(2)$ & $1(1)$ \\
\hline Leptodontidium orchidicola & HM036600 & 99 & & & $3(2)$ & $8(6)$ \\
\hline Fusarium solani & GU066713 & 100 & $7(3)$ & $4(2)$ & & $1(1)$ \\
\hline Cylindrocarpon destructans & AM419065 & 99 & & $7(4)$ & $4(3)$ & \\
\hline Colletotrichum pisi & GU724982 & 99 & & & $1(1)$ & \\
\hline Segment no. & & & 40 & 55 & 70 & 80 \\
\hline Total CF (NI) & & & $12(5)$ & $40(22)$ & $31(22)$ & $40(32)$ \\
\hline Species no. ${ }^{2)}$ & & & 2 & 6 & 8 & 5 \\
\hline
\end{tabular}

$\mathrm{NI}$ were in parentheses. The closest matched accession numbers were included after BLAST searches of ITS (internal transcribed spacer) sequences of fungal endophytes from the roots of 1-, 2-, 3-, and 4-year-old ginseng (Panax ginseng) plants. CF of endophytic fungi was calculated as follows: $\mathrm{CF}=\left(\mathrm{N}_{\mathrm{CoL}} / \mathrm{Nt}\right) \times 100$, where $\mathrm{N}_{\mathrm{CoL}}=$ number of segments colonized by each fungus; $\mathrm{Nt}=$ total number of segments.

ITS, internal transcribed spacer; $\mathrm{CF}$, colonization frequency; $\mathrm{NI}$, number of isolated fungal endophyte.

${ }^{1)}$ GenBank accession numbers of closest fungal sequence of ITS.

${ }^{2)}$ Species no. indicates the total numbers of species that were identified and unidentified in species level.

tract DNA from the ground mycelia. Universal eukaryotic primers were used to amplify the fungal ribosomal DNA internal transcribed spacer (ITS) regions 1 and 2 of all fungal isolates: ITS1 (5'-TCCGTAGGTGAACCTGCGG-3') and ITS4 (5'-TCCTCCGC TTATTGATATGC-3') [16]. The conditions used for polymerase chain reaction (PCR) reactions have been previously described [17]. ITS sequence information was obtained by the sequencing of the PCR products that were purified from the gel using Wizard SV gel and a PCR Clean-up System (Promega, Fitchburg, WI, USA) [18].

\section{Data analysis}

PCR-amplified ITS sequences were searched using the NCBI BLAST (http://www.ncbi.nlm.nih.gov) against those in the GenBank database and the results of matched accession numbers were included in Table 1. A phylogenetic tree was constructed using the Maximum Parsimony method and Mega5 software from ITS1-5.8SITS2 sequences (http://www.megasoftware.net) [19,20]. The phylogenetic tree was rooted with $S$. sclerotiorum as an outgroup fungal taxon. The colonization frequency
(CF) of endophytic fungi was calculated as follows: $\mathrm{CF}=\left(\mathrm{N}_{\mathrm{COL}} / \mathrm{Nt}\right) \times 100$, where $\mathrm{N}_{\mathrm{COL}}=$ number of segments colonized by each fungus; $\mathrm{Nt}=$ total number of segments. The percent of dominant endophyte (DE\%) was calculated as follows: $\mathrm{DE} \%=\left(\mathrm{N}_{\mathrm{f}} / \mathrm{N}_{\mathrm{t}}\right) \times 100$, where $\mathrm{N}_{\mathrm{f}}=$ number of each isolated fungus; $\mathrm{Nt}=$ total isolated number of fungi.

\section{RESULTS AND DISCUSSION}

This study was conducted to isolate fungal endophytes from ginseng roots of different ages. A total of 81 fungal endophytes were isolated from ginseng roots: 5, 22, 22, and 32 isolates from 1-, 2-, 3-, and 4-year-old ginseng roots, respectively (Table 1). The size of ITS-PCR products varied from 500 to $550 \mathrm{bp}$. Fungal endophytes were assigned to 9 different species and 2 unknown species. Ginseng roots of 1-, 2-, 3-, and 4-year-old plants were colonized by $2,6,8$, and 5 species of fungal endophytes, respectively (Table 1). The CF varied with the age of the host. Individual CFs were $12 \%, 40 \%, 31 \%$, and $40 \%$ for 1-, 2-, 3-, and 4-year-old ginseng roots, respectively. There were no significant differences in the dominant 


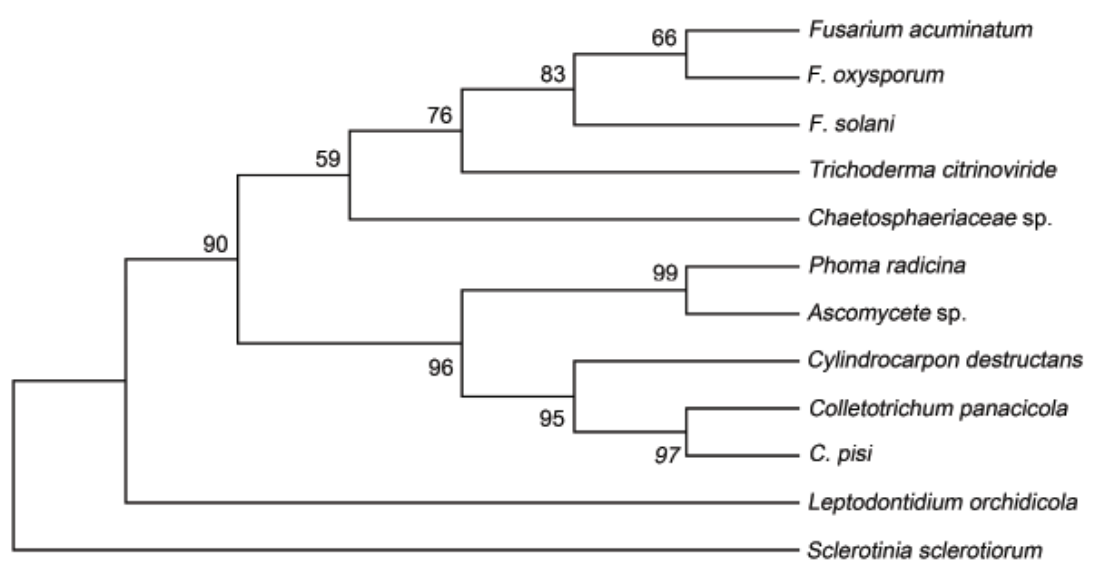

Fig. 1. Maximum-parsimony tree constructed from the internal transcribed spacer sequence of 11 taxa showing the relationships of fungal endophytes in Korean ginseng with reference taxa. The tree was rooted with Sclerotinia sclerotiorum (AB607227). The numbers at branches indicate the percentage of trees from 1,000 bootstrap replications. GenBank accession numbers are as follows: Trichoderma citrinoviride (HM776434), Colletotrichum panacicola (GU935869), Phoma radicina (FJ427058), unknown 1. (HM042312), Fusarium acuminatum (HM776425), unknown 2 ( AB499792), F. oxysporum (HM210092), Leptodontidium orchidicola (HM036600), F. solani (GU066713), Cylindrocarpon destructans (AM419065), C. pisi (GU724982).

fungal endophytes in different aged roots (Table 2). Phoma radicina was the most frequent fungal endophyte in 2-, 3-, and 4-year-old ginseng roots: $15 \%, 11 \%$, and $21 \%$ $\mathrm{CF}$, respectively. Percentages of dominant endophytes (DE) of $P$. radician in 2-, 3-, and 4-year-old ginseng were $37.5 \%, 38.5 \%$, and $52.5 \%$, respectively. Among 2 isolates detected, Fusarium solani was the dominant endophyte in 1-year-old ginseng roots: $7 \% \mathrm{CF}$ and $60 \%$ DE. In order to examine the biodiversity of the culturable fungal endophytes in ginseng roots, we analyzed the fungal ITS sequences. A total of 81 clones were obtained from the fungal endophytes isolated from 4 age groups of ginseng roots. The clones were sequenced and subjected to phylogenetic analysis. BLAST and MaximumParsimony phylogenetic tree analysis placed the cloned sequences into 11 groups (Fig. 1).

The isolated fungi described here include various fungi of Ascomycota. The isolated fungal endophytes belong to 11 fungal groups at different taxonomic levels based on ITS sequences and morphological identification. The genera of Phoma, Collectotrichum and Fusarium were the most common fungal endophytes found in ginseng roots cultivated in Korea, and are also common fungal endophytes found in P. quinquefolium, tropical, and subtropical plants [21]. We isolated $C$. destructans, which is one of the most harmful pathogenic fungi of ginseng. However, it is not clear whether $C$. destructans is pathogenic or nonpathogenic to ginseng. F. oxysporum is a common pathogenic fungus in plants; however, there are nonpathogenic strains that compete for organic substrates
Table 2. Percentage contribution by the DE to the fungal endophytes isolated from different ages including 1-, 2-, 3-, and 4-year-old ginseng roots

\begin{tabular}{clc}
\hline Age $(\mathrm{yr})$ & \multicolumn{1}{c}{ DE } & DE $(\%)^{1)}$ \\
\hline 1 & Fusarium solani & 60.0 \\
2 & Phoma radicina & 37.5 \\
3 & P. radicina & 38.5 \\
4 & P. radicina & 52.5 \\
\hline
\end{tabular}

$\mathrm{DE}$, dominant endophyte.

1) The percent of $\mathrm{DE}(\mathrm{DE} \%)$ was calculated as follows: $\mathrm{DE} \%=\left(\mathrm{N}_{\mathrm{f}} /\right.$ $\left.N_{t}\right) \times 100$, where $N_{t}=$ number of each isolated fungus; $N t=t o t a l$ isolated number of fungi.

with the pathogenic strains [22]. Nonpathogenic strains often reduce the germination of chlamydospores, and also germ tube growth, which leads to a decline in the population of pathogenic strains.

While higher numbers of fungal endophytes were detected in 4-year-old ginseng roots compared to 1-, 2and 3-year-old ginseng roots, a lower diversity of fungal endophytes was found in 4-year-old ginseng roots (Table 1). This may be due to differences in cultivation sites, age, and/or longer exposure to chemical fungicides in 4-year-old ginseng cultivation sites. Longer exposure to fungicides might reduce the total number of species of fungal endophytes, while resistant fungal species occupy ginseng roots more frequently. Similar results have been reported for the roots of $P$. quinquefolium [21]. Authors have explained the results by autotoxicity of $P$. quinquefolium. Autotoxic compounds in $P$. quinquefolium which have recently been isolated and characterized cause a 
reseeding failure [23]. These autotoxic compounds were also detected in soils used for ginseng cultivation in America [11]. Other factors can influence the community of fungal endophytes, such as fertilizers, water, temperature, soil, and plant defense compounds [24-26]. Fungi have common mechanisms used to detoxify compounds, such as activation of the membrane transporters that pump toxicants out of fungal cells, and enzymatic detoxification [27]. These detoxification mechanisms can be virulence factors for pathogens. Fungi that have detoxification mechanisms may increase their competitiveness among tolerant species of root endophytes, which leads to higher growth rates than those of less tolerant fungal endophytes in the presence of host toxins [28-31]. Colonization of mycorrhizal and soil fungi will be greatly affected when plant defense compounds are secreted in soil $[32,33]$.

Age specificity for fungal endophytes was found in ginseng roots. Only 3 species were common to 2-, 3-, and 4-year-old ginseng roots such as $P$. radicina, F. oxysporum, and unknown species 1.F. solani was the dominant species in 1-year-old ginseng roots, while it was not found in 3-year-old ginseng roots. Among 11 species, 5 were only detected in certain ages of ginseng roots, which included Trichoderma citrinoviride (1-year old), C. panacicola (2-year old), F. acuminatum (3-year old), Ascomycete sp. (3-year old), and unknown species 2 (3year old). A small number of fungal endophyte species was detected in 1-year-old $P$. ginseng roots compared to 1-year-old roots of P. quinquefolium (2 vs. 8) [21]. One possible explanation might be that endophytic communities are dependent on the cultivation environment and method as well as plant species [34]. Another reason might be the existence of $T$. citrinoviride. $T$. citrinoviride has a high ability to parasitize pathogens, protect host plants, and produce strongly inhibitory compounds. Many Trichoderma spp. produce a wide range of bioactive metabolites which contribute to their mycoparasitic and antibiotic actions [35]. The genera Phoma and Fusarium are ubiquitous in the environment and are famous as fungal pathogens [34]. In the current study, P. radicina was the dominant endophyte in 2-, 3-, and 4-year-old ginseng roots, while $F$. solani was the dominant endophyte in 1-year-old ginseng roots. Other studies also showed that Phoma and Fusarium are common fungal endophytes in plant species [36]. Endophytic Phoma is known to produce several bioactive compounds [37]. Endophytes have been known for their beneficial functions provided to plants regarding protection against abiotic and biotic stress [4]. In addition, endophytes are potential sources for the production of useful medicinal compounds [5,7,38]. For example, Taxomyces andreanae, a fungal endophyte isolated from the pacific Yew tree, can produce paclitaxel (Taxol; Bristol-Myers Squibb, New York, NY, USA) which is an important anticancer drug [38].

In conclusion, it is proposed that the diversity of fungal endophytes in ginseng roots is dependent on the age of the plant. Further studies are needed to understand the relationships between the host and endophytes at the molecular and genetic levels, and can lead to the better use of endophytes to protect plants and produce potential secondary metabolites.

\section{ACKNOWLEDGEMENTS}

This research was supported by a Yeungnam University Research Grant in 211-A-380-243.

\section{REFERENCES}

1. Aly AH, Debbab A, Proksch P. Fungal endophytes: unique plant inhabitants with great promises. Appl Microbiol Biotechnol 2011;90:1829-1845.

2. Schardl CL, Leuchtmann A, Spiering MJ. Symbioses of grasses with seedborne fungal endophytes. Annu Rev Plant Biol 2004;55:315-340.

3. Tan RX, Zou WX. Endophytes: a rich source of functional metabolites. Nat Prod Rep 2001;18:448-459.

4. Rodriguez RJ, White JF Jr, Arnold AE, Redman RS. Fungal endophytes: diversity and functional roles. New Phytol 2009;182:314-330.

5. Strobel G. Harnessing endophytes for industrial microbiology. Curr Opin Microbiol 2006;9:240-244.

6. Bony S, Pichon N, Ravel C, Durix A, Balfourier F, Guillaumin JJ. The relationship between mycotoxin synthesis and isolate morphology in fungal endophytes of Lolium perenne. New Phytol 2001;152:125-137.

7. Schulz B, Boyle C, Draeger S, Rommert AK, Krohn K. Endophytic fungi: a source of novel biologically active secondary metabolites. Mycol Res 2002;106:996-1004.

8. Choi KT. Botanical characteristics, pharmacological effects and medicinal components of Korean Panax ginseng C A Meyer. Acta Pharmacol Sin 2008;29:1109-1118.

9. Shim M, Lee YJ. Ginseng as a complementary and alternative medicine for postmenopausal symptoms. J Ginseng Res 2009;33:89-92.

10. Kim MH, Hong HD, Kim YC, Rhee YK, Kim KT, Rho J. Ginsenoside changes in red ginseng manufactured by acid impregnation treatment. J Ginseng Res 2010;34:93-97. 
11. He CN, Gao WW, Yang JX, Bi W, Zhang XS, Zhao YJ. Identification of autotoxic compounds from fibrous roots of Panax quinquefolium L. Plant Soil 2009;318:63-72.

12. Leung KW, Wong AS. Pharmacology of ginsenosides: a literature review. Chin Med 2010;5:20.

13. Cho NS, Kim DH, Cho HY, Shin YS, Kim YC, Ohga S. Identification of symbiotic arbuscular mycorrhizal fungi in Korean ginseng roots by $18 \mathrm{~S}$ rDNA sequence. J Fac Agric Kyushu Univ 2007;52:265-274.

14. Li TS. Evaluation of chemical and non-chemical treatments for the control of ginseng replant disease. Acta Hortic (ISHS) 1994;363:141-146.

15. Rural Development Administration. Ginseng GAP standard cultivation guideline. Suwon: National Institute of Crop Science, 2009.

16. White TJ, Bruns T, Lee S, Taylor JW. Amplification and direct sequencing of fungal genes for phylogenetics, In: Innis MA, Gelfand DH, Sninsky JJ, White TJ, eds. PCR protocols: a guide to methods and applications. San Diego: Academic Press, 1990. p.315-322.

17. Park SU, Lim HS, Park KC, Park YH, Bae HH. Fungal endophytes from three cultivars of Panax ginseng Meyer cultivated in Korea. J Ginseng Res 2012;36:107-113.

18. Quilliam RS, Jones DL. Fungal root endophytes of the carnivorous plant Drosera rotundifolia. Mycorrhiza 2010;20:341-348.

19. Dreyfuss MM, Chapela IH. Potential of fungi in the discovery of novel, low molecular weight pharmaceuticals. In: Gullo VP, ed. The discovery of natural products with therapeutic potential. Boston: Butterworth-Heinemann, 1994. p.49-80.

20. Rodriguez R, Redman R. More than 400 million years of evolution and some plants still can't make it on their own: plant stress tolerance via fungal symbiosis. J Exp Bot 2008;59:1109-1114.

21. Xing X, Guo S, Fu J. Biodiversity and distribution of endophytic fungi associated with Panax quinquefolium L. cultivated in a forest reserve. Symbiosis 2010;51:161166.

22. Fravel D, Olivain C, Alabouvette C. Fusarium oxysporum and its biocontrol. New Phytol 2003;157:493-502.

23. Zhao YJ, Wang YP, Shao D, Yang JS, Liu D. Autotoxicity of Panax quinquefolium L. Allelophath J 2005;15:67-74.

24. Seghers D, Wittebolle L, Top EM, Verstraete W, Siciliano SD. Impact of agricultural practices on the Zea mays L. endophytic community. Appl Environ Microbiol 2004;70:1475-1482.

25. Marin S, Companys E, Sanchis V, Ramos AJ, Magan N. Effect of water activity and temperature on competing abilities of common maize fungi. Mycol Res
1998;102:959-964.

26. Niemeyer HM, Perez FJ. Potential of hydroxamic acids in the control of cereal pests, diseases and weeds. In: Inderjit, Daksini KM, Einhellig FA, eds. Allelopathy: organisms, processes, and applications. Washington, DC: American Chemical Society, 1995. p.260-270.

27. VanEtten H, Temporini E, Wasmann C. Phytoalexin (and phytoanticipin) tolerance as a virulence trait: why is it not required by all pathogens? Physiol Mol Plant Pathol 2001;59:83-93.

28. Carter JP, Spink J, Cannon PF, Daniels MJ, Osbourn AE. Isolation, characterization, and avenacin sensitivity of a diverse collection of cereal-root-colonizing fungi. Appl Environ Microbiol 1999;65:3364-3372.

29. Arnold AE, Mejia LC, Kyllo D, Rojas EI, Maynard Z, Robbins N, Herre EA. Fungal endophytes limit pathogen damage in a tropical tree. Proc Natl Acad Sci U S A 2003;100:15649-15654.

30. Nicol RW, Yousef L, Traquair JA, Bernards MA. Ginsenosides stimulate the growth of soilborne pathogens of American ginseng. Phytochemistry 2003;64:257-264.

31. Saunders M, Kohn LM. Host-synthesized secondary compounds influence the in vitro interactions between fungal endophytes of maize. Appl Environ Microbiol 2008;74:136-142.

32. Stinson KA, Campbell SA, Powell JR, Wolfe BE, Callaway RM, Thelen GC, Hallett SG, Prati D, Klironomos JN. Invasive plant suppresses the growth of native tree seedlings by disrupting belowground mutualisms. PLoS Biol 2006;4:e140.

33. Broeckling CD, Broz AK, Bergelson J, Manter DK, Vivanco JM. Root exudates regulate soil fungal community composition and diversity. Appl Environ Microbiol 2008;74:738-744.

34. Aveskamp MM, De Gruyter J, Crous PW. Biology and recent developments in the systematics of Phoma, a complex genus of major quarantine significance. Fungal Divers 2008;31:1-18.

35. Maddau L, Cabras A, Franceschini A, Linaldeddu BT, Crobu S, Roggio T, Pagnozzi D. Occurrence and characterization of peptaibols from Trichoderma citrinoviride, an endophytic fungus of cork oak, using electrospray ionization quadrupole time-of-flight mass spectrometry. Microbiology 2009;155(Pt 10):3371-3381.

36. Schulz B, Boyle C. The endophytic continuum. Mycol Res 2005;109(Pt 6):661-686.

37. Wang LW, Xu BG, Wang JY, Su ZZ, Lin FC, Zhang CL, Kubicek CP. Bioactive metabolites from Phoma species, an endophytic fungus from the Chinese medicinal plant Arisaema erubescens. Appl Microbiol Biotechnol 
2012;93:1231-1239.

38. Zhou X, Zhu H, Liu L, Lin J, Tang K. A review: recent advances and future prospects of taxol-producing endo- phytic fungi. Appl Microbiol Biotechnol 2010;86:17071717. 